\title{
Clinical efficacy of PVP and PKP in the treatment of OVCFs after bilateral resection of ovarian cancer
}

\author{
SHAOQIAN WANG ${ }^{*}$, HUI WANG ${ }^{*}$ and LEI NIU \\ Department of Micro-Orthopaedics, The Second People's Hospital of Hefei, Hefei, Anhui 230011, P.R. China
}

Received December 13, 2017; Accepted March 2, 2018

DOI: $10.3892 / 01.2018 .8658$

\begin{abstract}
The clinical efficacy of percutaneous vertebroplasty (PVP) and percutaneous kyphoplasty (PKP) in the treatment of osteoporotic vertebral compression fractures after bilateral resection of ovarian cancer was investigated. Eighty-six patients with osteoporotic vertebral compression fractures after bilateral resection of ovarian cancer admitted to the Second People's Hospital of Hefei from September, 2015 to August, 2016 were selected and randomly divided into control group $(n=43)$ and observation group $(n=43)$. The control group was treated with PVP, while the observation group received PKP. The operation time, fluoroscopy times, bone cement volume and leakage rate of patients in the two groups were recorded; the postoperative pain of patients was compared using Short-form McGill Pain Questionnaire; the changes in height of injured vertebra and Cobb angle of patients in two groups were compared; the efficacy of patients in the two groups was compared in accordance with Oswestry dysfunction index (ODI) and Japanese Orthopedic Association (JOA) low back pain scoring; and the quality of life was compared. The fluoroscopy times and bone cement leakage were significantly less in observation group than those in control group $(\mathrm{P}<0.05)$. After operation, the scores of ODI, MPQ and JOA in the two groups were significantly improved $(\mathrm{P}<0.05)$. The postoperative height of injured vertebra and the Cobb angle of patients in two groups were significantly different than those before the operation $(\mathrm{P}<0.05)$. The quality of life of patients in the observation group was higher than that in the control group one year after operation $(\mathrm{P}<0.05)$. In conclusion, PKP and PVP are effective in the treatment of osteoporotic vertebral compression fractures after bilateral resection of ovarian cancer; however, $\mathrm{PKP}$ is more conducive to lumbar stability and maintenance of intervertebral height
\end{abstract}

Correspondence to: Dr Lei Niu, Department of Micro-Ortho paedics, The Second People's Hospital of Hefei, 246 Heping Road, Hefei, Anhui 230011, P.R. China

E-mail:m13365792992@163.com

${ }^{*}$ Contributed equally

Key words: osteoporotic vertebral compression fractures, PVP, PKP, bilateral resection of ovarian cancer thus greatly correcting the kyphosis, which is beneficial to improving the quality of life of patients.

\section{Introduction}

Ovarian cancer is a common malignant tumor in women. In recent years, the incidence of ovarian cancer is increasing and shows younger trend, and its mortality is the highest among gynecological malignancies (1). Bilateral ovarian resection is an important therapy for ovarian cancer, but the operation will sharply decrease estrogen in patients, increase osteoclastogenesis and inhibit bone absorption, leading to the reduction of patients' bone density and resulting in osteoporosis (OP) (2). Fracture easily occurs in OP patients, and the spine bears most of the stress, so vertebral compression fractures are the most common, which is known as osteoporotic vertebral compression fractures (OVCFs) (3). The clinical symptoms of OVCF patients after bilateral ovarian resection are not typical at the initial stage. It is difficult to arouse the attention of patients, but it will lead to spinal deformity over time, and eventually bring great pain to the patients, which not only brings heavy financial burden to the family, but also directly affects the quality of life of patients, so it should be paid great attention (4). OVCFs are clinically administered by conservative treatment and surgical treatment; therein, percutaneous vertebroplasty (PVP) and percutaneous kyphoplasty (PKP), these two minimally invasive surgery modes, are mainly utilized at present, which display remarkable clinical efficacies, and the latter is developed on the basis of the former (5). In this study, patients with OVCFs after bilateral resection of ovarian cancer were treated with PVP and PKP, and the efficacy and safety of two surgical procedures were analyzed, so as to provide basis for the treatment of OVCFs, which is reported as follows.

\section{Materials and methods}

Clinical data. Eighty six patients with OVCFs after bilateral resection of ovarian cancer admitted to the Second People's Hospital of Hefei (Hefei, China) from September, 2015 to August, 2016 were selected. Inclusion criteria: i) Patients received bilateral resection of ovarian cancer; ii) OVCFs were diagnosed by X-ray examination; iii) bone density examination showed $\mathrm{T}<-2.5$; and iv) patients signed the written informed consent. Exclusion criteria: i) Patients with severe osteomalacia or osteoporosis; and ii) patients with coagulation 
Table I. Baseline data of patients in the groups.

\begin{tabular}{lcccr}
\hline Item & $\begin{array}{c}\text { Control group } \\
(\mathrm{n}=43)\end{array}$ & $\begin{array}{c}\text { Observation group } \\
(\mathrm{n}=43)\end{array}$ & $\mathrm{t} / \chi^{2}$ value & P-value \\
\hline Age (years) & $30-60$ & $30-65$ & & \\
Average age (years) & $41.56 \pm 5.42$ & $42.85 \pm 5.38$ & 1.108 & 0.271 \\
Bone density (T) & $-2.93 \pm 0.46$ & $-2.98 \pm 0.48$ & 0.493 & 0.623 \\
Body mass index $\left(\mathrm{kg} / \mathrm{m}^{2}\right)$ & $22.83 \pm 1.54$ & $22.56 \pm 1.27$ & 0.887 & 0.378 \\
Fracture site $(\mathrm{n}, \%)$ & & & & 0.902 \\
$\quad$ Cervical vertebra & $8(18.60)$ & $7(16.28)$ & & \\
Thoracic vertebra & $18(41.86)$ & $17(39.53)$ & & \\
Lumbar vertebra & $17(39.53)$ & $19(44.19)$ & & \\
\hline
\end{tabular}

disorders. The enrolled patients were divided into observation group ( $\mathrm{n}=43)$ and control group $(\mathrm{n}=43)$ using a random number table. The differences in general data of patients between the groups were not statistically significant $(\mathrm{P}>0.05)$ (Table I). The study was approved by the Ethics Committee of the Second People's Hospital of Hefei. All patients have provided written informed consent for publication.

Preoperative preparation. Patients were comprehensively evaluated before surgery, and excluded due to surgical contraindications, and then appropriate timing of surgery was selected. Patients were administrated with antibiotics to prevent infection $2 \mathrm{~h}$ before operation, and fasting for $8 \mathrm{~h}$ and fasting with liquid for $6 \mathrm{~h}$ were required before operation.

Treatment. The control group was treated with PVP, of which patients were guided to take prone position, blocking up the chest and bilateral iliums, and blood pressure, electrocardiograph and blood oxygen were monitored. The affected vertebra was identified by $\mathrm{C}$-arm machine, and then marked. Draping and disinfection were routinely prepared, the puncture was conducted outside the vertebral pedicle. Lidocaine infiltration (2\%) was adopted for anesthesia, followed by transpedicular approach for puncture from the left side, until the correct position through observation using $\mathrm{C}$-arm machine fluoroscopy. After the successful puncture, the inner core of puncture needle was extracted. Subsequently, $20 \mathrm{~g}$ bone cement powder [manufacturer: Heraeus Medical GmbH; registration no.: State Food and Drug Administration (Import) 2011; no. 3652798] was modulated well and slowly injected into the affected vertebra. When the bone cement in vertebra was diffused to the posterior margin of the vertebral body or bone cement leakage was found, injection was stopped. After surgery, patients were guided to have bed rest for $10 \mathrm{~min}$, followed by compression and dressing with needle tract sterile materials after bone cement hardened completely.

The observation group received PKP. The positioning, puncture and other operations were the same as those in PVP. Before bone cement was modulated, the balloon dilatation catheter was placed at $1 / 3$ the front of vertebral body. Under the monitoring by $\mathrm{C}$-arm machine, the balloon was slowly dilated, followed by injection with contrast agent. The pressure of the balloon was less than $250 \mathrm{mmHg}$. When the height reset of the vertebral body was satisfactory, the contrast agent was stopped. The balloon was withdrawn as contrast agent was extracted, followed by injection of the modulated bone cement. The method was the same as that of PVP.

Postoperative processing and follow-up. Rest in supine position was required for patients after operation, and X-ray examination was carried out to observe the diffusion of bone cement and whether there was bone cement leakage. Antibiotic prophylaxis was administered to patients within $24 \mathrm{~h}$, and out of bed activities with wearing a corset was performed after $24 \mathrm{~h}$. Weight-bearing and lifting heavy weights were not allowed. Patients were followed-up for one year to observe the rehabilitation.

Evaluation methods. The operation conditions including operation time, fluoroscopy times, bone cement volume and leakage rate of patients in two groups were compared. During 12 months of the follow-up, Osteoporosis Quality of Life Scale (OQOLS) was utilized (6) to complete the scoring in accordance with grade 0-5-point method from disease (17 items), physiology (20 items), society (19 items), psychology (13 items) and degree of satisfaction (6 items). The score was positively correlated with quality of life.

The preoperative and postoperative dysfunction of patients were scored using Oswestry dysfunction index (ODI) (7) according to $0-5$-point method (0 point: No dysfunction; 5 points: Most obvious dysfunction) from individual ability, pain and personal comprehensive ability, three dimensions, a total of 9 items. The ODI value was positively correlated with the degree of dysfunction. The preoperative and postoperative low back pain of patients was scored in accordance with Japanese Orthopedic Association Scale (JOA) (8), a total of 29 points.

The joint pain of patients was assessed using Short-form McGill Pain Questionnaire (SF-MPQ) before operation and at postoperative 1, 6 and 12 months (9): Scoring from pain rating index (PRI), visual analogue scale (VAS) and present pain intensity (PPI). The points accumulated by these three parts were the final total score. The total score was positively correlated with degree of pain.

The changes in height of the affected vertebra were measured preoperatively and at 1 and 3 months after operation: 
Table II. Comparisons of operation conditions in patients between two groups.

\begin{tabular}{|c|c|c|c|c|c|}
\hline Group & Case & $\begin{array}{l}\text { Operation } \\
\text { time (min) }\end{array}$ & $\begin{array}{l}\text { Bone cement } \\
\text { volume }(\mathrm{ml})\end{array}$ & $\begin{array}{c}\text { Fluoroscopy times } \\
\text { (times) }\end{array}$ & $\begin{array}{l}\text { Bone cement } \\
\text { leakage }(n, \%)\end{array}$ \\
\hline Observation group & 43 & $34.83 \pm 3.62$ & $3.97 \pm 1.43$ & $10.86 \pm 1.45$ & $4(9.30)$ \\
\hline Control group & 43 & $35.14 \pm 3.56$ & $3.89 \pm 1.38$ & $13.97 \pm 1.37$ & $13(30.23)$ \\
\hline $\mathrm{t} / \chi^{2}$ value & & 0.400 & 0.264 & 10.223 & 4.692 \\
\hline P-value & & 0.690 & 0.792 & $<0.001$ & 0.030 \\
\hline
\end{tabular}

Table III. Comparisons of preoperative and postoperative ODI scores in patients between two groups.

\begin{tabular}{|c|c|c|c|c|c|c|c|}
\hline Group & Case & $\begin{array}{c}\text { Before } \\
\text { operation }\end{array}$ & $\begin{array}{c}\text { Postoperative } \\
1 \text { month }\end{array}$ & $\begin{array}{l}\text { Postoperative } \\
6 \text { months }\end{array}$ & $\begin{array}{l}\text { Postoperative } \\
12 \text { months }\end{array}$ & F-value & P-value \\
\hline Observation group & 43 & $30.89 \pm 3.26$ & $11.47 \pm 3.63$ & $5.75 \pm 2.26$ & $4.12 \pm 2.23$ & 47.648 & $<0.001$ \\
\hline Control group & 43 & $31.25 \pm 3.34$ & $13.59 \pm 3.37$ & $6.93 \pm 2.36$ & $5.78 \pm 2.37$ & 41.704 & $<0.001$ \\
\hline t-value & & 0.506 & 2.807 & 2.368 & 3.345 & & \\
\hline P-value & & 0.614 & 0.006 & 0.020 & 0.001 & & \\
\hline
\end{tabular}

Table IV. Comparisons of preoperative and postoperative ODI scores in patients between two groups.

\begin{tabular}{|c|c|c|c|c|c|c|c|}
\hline Group & Case & $\begin{array}{c}\text { Before } \\
\text { operation }\end{array}$ & $\begin{array}{l}\text { Postoperative } \\
1 \text { month }\end{array}$ & $\begin{array}{l}\text { Postoperative } \\
6 \text { months }\end{array}$ & $\begin{array}{l}\text { Postoperative } \\
12 \text { months }\end{array}$ & F-value & P-value \\
\hline Observation group & 43 & $2.82 \pm 0.35$ & $4.57 \pm 0.36$ & $4.57 \pm 0.35$ & $6.25 \pm 0.36$ & 19.624 & $<0.001$ \\
\hline Control group & 43 & $2.78 \pm 0.36$ & $3.32 \pm 0.34$ & $3.33 \pm 0.32$ & $4.87 \pm 0.34$ & 9.829 & $<0.001$ \\
\hline t-value & & 0.522 & 16.553 & 17.146 & 18.275 & & \\
\hline P-value & & 0.603 & $<0.001$ & $<0.001$ & $<0.001$ & & \\
\hline
\end{tabular}

The anterior margin and middle height of the vertebral body on the X-ray lateral radiograph were measured, and the measured value was converted into the actual length according to the chip scale. The changes in vertebral kyphosis Cobb angle before and after operation were measured, which was obtained by measuring the corner of the up and down endplate vertical line of affected vertebra on the X-ray lateral radiograph.

Statistical analysis. Data were processed by SPSS 19.0 (SPSS Inc., Chicago, IL, USA) software. Measurement data were expressed as mean \pm standard deviation and analyzed by t-test. Enumeration data were represented by rate and analyzed by Chi-square test. Rank-sum test was used for ranked data. $\mathrm{P}<0.05$ was considered to indicate a statistically significant difference.

\section{Results}

Comparison of the operation and postoperative conditions in patients in the groups. There were no remarkable differences in operation time and bone cement volume in patients between the groups $(\mathrm{P}>0.05)$. The fluoroscopy times were significantly less in observation group than those in control group, and bone cement leakage in observation group was distinctly lower than that in control group $(\mathrm{P}<0.05)$ (Table II).
Comparison of preoperative and postoperative ODI scores in patients between two groups. The ODI scores of patients in two groups were significantly ameliorated at postoperative 1,6 and 12 months, and the scores in observation group were remarkably superior to those in control group $(\mathrm{P}<0.05)$ (Table III).

Comparison of preoperative and postoperative JOA scores in patients between two groups. The JOA scores of patients in two groups were remarkably improved at postoperative 1,6 and 12 months, and the scores in observation group were obviously superior to those in control group $(\mathrm{P}<0.05)$ (Table IV).

Comparison of postoperative MPQ scores in patients between two groups. The MPQ scores of patients in two groups were significantly ameliorated at postoperative 1, 6 and 12 months, and the scores in observation group were distinctly superior to those in control group $(\mathrm{P}<0.05)$ (Table $\mathrm{V})$.

Comparison of changes in height of the injured vertebra before and after operation in patients between two groups. The changes in observation group were remarkably better than those in control group at postoperative 1 and 3 months, and the differences were statistically significant $(\mathrm{P}<0.05)$ (Table VI). 
Table V. Comparison of postoperative MPQ scores in patients between two groups.

\begin{tabular}{|c|c|c|c|c|c|c|c|}
\hline Group & Case & $\begin{array}{c}\text { Before } \\
\text { operation }\end{array}$ & $\begin{array}{l}\text { Postoperative } \\
1 \text { month }\end{array}$ & $\begin{array}{l}\text { Postoperative } \\
6 \text { months }\end{array}$ & $\begin{array}{l}\text { Postoperative } \\
12 \text { months }\end{array}$ & F-value & $\mathrm{P}$-value \\
\hline Observation group & 43 & $56.95 \pm 3.15$ & $36.85 \pm 3.16$ & $18.56 \pm 3.18$ & $9.16 \pm 3.15$ & 57.638 & $<0.001$ \\
\hline Control group & 43 & $57.16 \pm 3.26$ & $48.06 \pm 3.24$ & $24.63 \pm 3.22$ & $16.28 \pm 3.14$ & 51.527 & $<0.001$ \\
\hline t-value & & 0.304 & 16.242 & 8.795 & 10.497 & & \\
\hline P-value & & 0.762 & $<0.001$ & $<0.001$ & $<0.001$ & & \\
\hline
\end{tabular}

Table VI. Comparisons of changes in height of the injured vertebra before and after operation in patients between two groups.

\begin{tabular}{|c|c|c|c|c|c|c|}
\hline Group & Case & $\begin{array}{c}\text { Before } \\
\text { operation }\end{array}$ & $\begin{array}{l}\text { Postoperative } \\
1 \text { month }\end{array}$ & $\begin{array}{l}\text { Postoperative } \\
3 \text { months }\end{array}$ & F-value & P-value \\
\hline Observation group & 43 & $22.62 \pm 2.34$ & $25.56 \pm 2.37$ & $29.24 \pm 2.47$ & 13.518 & $<0.001$ \\
\hline Control group & 43 & $22.74 \pm 2.36$ & $24.34 \pm 2.38$ & $25.89 \pm 2.43$ & 8.521 & $<0.001$ \\
\hline t-value & & 0.237 & 2.382 & 6.340 & & \\
\hline P-value & & 0.813 & 0.019 & $<0.001$ & & \\
\hline
\end{tabular}

Table VII. Comparisons of changes in Cobb angle before and after operation in patients between two groups.

\begin{tabular}{|c|c|c|c|c|c|c|}
\hline Group & Case & $\begin{array}{c}\text { Before } \\
\text { operation }\end{array}$ & $\begin{array}{l}\text { Postoperative } \\
1 \text { month }\end{array}$ & $\begin{array}{l}\text { Postoperative } \\
3 \text { months }\end{array}$ & F-value & P-value \\
\hline Observation group & 43 & $22.25 \pm 1.37$ & $20.76 \pm 1.05$ & $17.34 \pm 0.76$ & 11.818 & $<0.001$ \\
\hline Control group & 43 & $22.31 \pm 1.38$ & $18.32 \pm 1.03$ & $13.49 \pm 0.84$ & 9.706 & $<0.001$ \\
\hline t-value & & 0.202 & 10.878 & 22.287 & & \\
\hline P-value & & 0.840 & $<0.001$ & $<0.001$ & & \\
\hline
\end{tabular}

Comparisons of changes in Cobb angle before and after operation in patients between two groups. The changes in observation group were remarkably better than those in control group at postoperative 1 and 3 months, and the differences were statistically significant $(\mathrm{P}<0.05)$ (Table VII).

Comparison of quality of life in patients between two groups during one year of follow-up after operation. The quality of life scores at various dimensions were significantly higher in observation group than those in control group $(\mathrm{P}<0.05)$ (Table VIII).

\section{Discussion}

Osteoporosis (OP) may occur after bilateral resection of ovarian cancer in women due to its hormone-dependent manner in patients, and estrogen will decrease greatly after operation. Generally, the human skeleton is estrogen-dependent. Normally, estrogen effectively inhibits the differentiation and activation of osteoclasts, thus reducing the occurrence of bone loss, and maintains a dynamic balance between bone absorption and formation, thereby reducing the occurrence of fractures $(10,11)$. The rapid decrease of estrogen caused by bilateral resection of ovarian cancer accelerates the proliferation and differentiation of osteoclast precursors, and increases osteoclast activity, which leads to greater bone absorption than bone formation, thus inducing OP (12). In addition to the effect by estrogen, it is also correlated with the way of postoperative exercise, diet and psychological factors. The lumbar vertebra is the most stressed part of the human spine; due to the loss of bone tissue, destruction of bone tissue microstructure and thinning of cortical bone, once patients are affected by turning back, carrying heavy weights, moving objects or other violence activities, thoracolumbar spine is more prone to fracture (13).

With the application of minimally invasive technique in the Department of Orthopedics, PVP has been widely used in clinical practice of orthopedics, PKP has also been applied in clinic, and both are proved to be effective methods for the treatment of osteoporotic compression fractures; there are similarities and differences between them (14). The results of the study showed that there were no remarkable differences in operation time and bone cement volume in patients between two groups $(\mathrm{P}>0.05)$; the fluoroscopy times were significantly less in observation group than those in control group, and bone cement leakage in observation group was distinctly lower than that in control group $(\mathrm{P}<0.05)$. This is because the use of minimally invasive techniques for bone cement infusion into 
Table VIII. Comparison of quality of life in patients between two groups.

\begin{tabular}{|c|c|c|c|c|c|c|}
\hline Group & Case & Disease & Physiology & Society & Psychology & Degree of satisfaction \\
\hline Observation group & 43 & $63.82 \pm 3.34$ & $53.56 \pm 3.35$ & $54.26 \pm 3.56$ & $28.24 \pm 3.36$ & $38.26 \pm 3.26$ \\
\hline Control group & 43 & $52.78 \pm 3.32$ & $45.34 \pm 3.36$ & $46.79 \pm 3.44$ & $21.89 \pm 3.34$ & $30.69 \pm 3.25$ \\
\hline t-value & & 15.372 & 11.361 & 9.895 & 8.789 & 10.784 \\
\hline P-value & & $<0.001$ & $<0.001$ & $<0.001$ & $<0.001$ & $<0.001$ \\
\hline
\end{tabular}

the injured vertebra, and there is no distinct difference in bone cement volume; however, the balloon needs to be expanded before cement modulation in PKP, and bone cement infusion is required to be more direct and accurate, so as to reduce the fluoroscopy times and the permeability rate of bone cement in the late stage (15).

OVCFs have a profound impact on patients with spinal kyphosis and lumbar back pain; if not treated in time, patients will suffer persistent pain, needing treatment with analgesic drugs daily to maintain normal life; not only does it increase the financial burden, but it also has a serious impact on the physical and mental health and the quality of life (16). The results of this study show that there were no significant differences in preoperative ODI, MPQ and JOA scores between the two groups ( $P>0.05)$, and after operation, the scores of ODI, MPQ and JOA in the two groups were significantly improved, which were more obvious in the observation group than those in the control group $(\mathrm{P}<0.05)$. This is because patients do not take bed rest, and a sharp pain is felt even when turning over or being touched; when people suffer from OVCFs, spinal kyphosis will occur, which leads to loss of normal curvature and changes in spinal endurance, thus enhancing compression force of injured vertebra and more obvious pain; the nerve involvement of lesions will cause neurological dysfunction, and OP itself can also incur pain in patients (17). After treatment with PVP and PKP, the concretion of bone cement blocks the blood of the diseased part of the vertebra, thereby reducing the pressure at the fracture site and enhancing the stability of the fracture site; in addition, the chemical reaction during the coagulation process produces heat, which destroys the nerve endings around the fracture and reduces the nerve irritation caused by the movement of the fracture site, thereby achieving analgesic effects (18). Through balloon dilatation, PKP can compress the spongy bone around the fracture, so that bone trabecula becomes relatively dense, so as to effectively alleviate dysfunction, and it also can effectively reduce the leakage of bone cement, thus reducing the paraspinal muscle tissue damage and decreasing postoperative local pain.

The results of this study indicated that the height of the injured vertebra and the Cobb angle of patients in two groups were significantly different from those before the operation $(\mathrm{P}<0.05)$, and the change in observation group was more distinct from those in control group $(\mathrm{P}>0.05)$. This is because after PVP and PKP treatment, the diffusion of bone cement at bone fracture will reinforce the bone strength of the injured vertebra and can reset the vertebral compression fracture, thus restoring part of the injured vertebra height; with the height of the injured vertebra restored, the Cobb angle also recovered (19). Through the balloon dilatation, the viscosity bone cement perfusion under low pressure in PKP treatment is higher, and the local mechanical effect of bone cement increases; balloon dilation also can effectively support the collapse, which shows a significant effect of reset, thus recovering the height of injured vertebra to the utmost and remarkably correcting spinal kyphosis (20). Through the treatment of PVP and PKP, the local tissue burden is increased, the pain of patients is alleviated effectively, and the kyphosis is also corrected, so that the patients return to normal activities and their quality of life is effectively improved.

In summary, PKP and PVP are effective in the treatment of osteoporotic vertebral compression fractures after bilateral resection of ovarian cancer, but compared with PVP, PKP can effectively relieve the pain in patients, recover the height of injured vertebra and correct spinal kyphosis, and the incidence of bone cement leakage is also lower. However, due to the limited sample size, data bias is unavoidable, and long-term efficacy still needs to be further observed.

\section{Acknowledgements}

Not applicable.

\section{Funding}

No funding was received.

\section{Availability of data and material}

The datasets analyzed during the current study are not publicly available due to the protection of patient privacy but are available from the corresponding author on reasonable request.

\section{Authors' contributions}

SW and HW collected the patient clinical information and analyzed the data. SW wrote the manuscript and $\mathrm{LN}$ revised and edited the manuscript. LN evaluated and analyzed the operation conditions. All authors read and approved the final manuscript.

\section{Ethics approval and consent to participate}

This study was approved by the Ethics Committee of The Second People's Hospital of Hefei (Hefei, China). All patients have provided written informed consent for publication.

\section{Consent for publication}

Not applicable. 


\section{Competing interests}

The authors declare that they have no competing interests.

\section{References}

1. Williams RS, Littell RD and Mendenhall NP: Laparoscopic oophoropexy and ovarian function in the treatment of Hodgkin disease. Cancer 86: 2138-2142, 1999.

2. Cairoli E,Eller-Vainicher C and Chiodini I: Update on denosumab in the management of postmenopausal osteoporosis: Patient preference and adherence. Int J Womens Health 7: 833-839, 2015.

3. Masala S, Magrini A, Taglieri A, Nano G, Chiaravalloti A, Calabria E, Di Trapano R, Pietroiusti A and Simonetti G: Chronic obstructive pulmonary disease (COPD) patients with osteoporotic vertebral compression fractures (OVCFs): Improvement of pulmonary function after percutaneous vertebroplasty (VTP). Eur Radiol 24: 1577-1585, 2014.

4. Kan SL, Yuan ZF, Chen LX, Sun JC, Ning GZ and Feng SQ: Which is best for osteoporotic vertebral compression fractures: Balloon kyphoplasty, percutaneous vertebroplasty or non-surgical treatment? A study protocol for a Bayesian network meta-analysis. BMJ Open 7: e012937, 2017.

5. Zhao G, Liu X and Li F: Balloon kyphoplasty versus percutaneous vertebroplasty for treatment of osteoporotic vertebral compression fractures (OVCFs). Osteoporos Int 27: 2823-2834, 2016.

6. Li Y, Zhao WB, Wang DL, He Q, Li Q, Pei FX and Liu L: Treatment of osteoporotic intertrochanteric fractures by zoledronic acid injection combined with proximal femoral nail anti-rotation. Chin J Traumatol 19: 259-263, 2016.

7. Grandidge L, Athanassacopolous M, Breakwell L, Chiverton N, Ivanov M, Michael R, Zaki H and Cole A: Oswestry Disability Index (ODI) and Visual Analogue Score (VAS) in pre-operative patients with radicular leg pain. Spine J 15: S53-S54, 2015.

8. Makino T, Kaito T, Kashii M, Iwasaki M and Yoshikawa $\mathrm{H}$ Low back pain and patient-reported QOL outcomes in patients with adolescent idiopathic scoliosis without corrective surgery. Springerplus 4: 397, 2015.

9. Kachooei AR, Ebrahimzadeh MH, Erfani-Sayyar R, Salehi M, Salimi E and Razi S: Short Form-McGill Pain Questionnaire-2 (SF-MPQ-2): A Cross-Cultural Adaptation and Validation Study of the Persian Version in Patients with Knee Osteoarthritis. Arch Bone Jt Surg 3: 45-50, 2015.

10. Jeremiah MP, Unwin BK, Greenawald MH and Casiano VE: Diagnosis and management of osteoporosis. Am Fam Physician 92: 261-268, 2015.
11. Reinhardt RA, Payne JB, Maze CA, Patil KD, Gallagher SJ and Mattson JS: Influence of estrogen and osteopenia/osteoporosis on clinical periodontitis in postmenopausal women. J Periodontol 70: 823-828, 1999.

12. Tanaka T, Latorre MRDO, Jaime PC, Florindo AA, Pippa MG and Zerbini CA: Risk factors for proximal femur osteoporosis in men aged 50 years or older. Osteoporos Int 12: 942-949, 2001.

13. Zhang L, Liu Z, Wang J, Feng X, Yang J, Tao Y and Zhang S: Unipedicular versus bipedicular percutaneous vertebroplasty for osteoporotic vertebral compression fractures: A prospective randomized study. BMC Musculoskelet Disord 16: 145, 2015.

14. Qu HB, Tong PJ, Ji WF and Li J: Percutaneous kyphoplasty for the treatment of osteoporotic vertebral compression fracture with degenerative scoliosis. Zhongguo Gu Shang 29: 38-40, 2016 (In Chinese).

15. Wang H, Sribastav SS, Ye F, Yang C, Wang J, Liu H and Zheng Z: Comparison of percutaneous vertebroplasty and balloon kyphoplasty for the treatment of single level vertebral compression fractures: A meta-analysis of the literature. Pain Physician 18: 209-222, 2015

16. Kim JO, Han SH, Lee YH, Ahn TK, Lim JJ, Chung YS, Shin DE, Lee WS, Han IB and Kim NK: Association of plasminogen activator inhibitor-1 (PAI-1) gene polymorphisms with osteoporotic vertebral compression fractures (OVCFs) in postmenopausal women. Int J Mol Sci 17: 2062, 2016.

17. Sheng S, Zhenzhong S, Weimin J, Yimeng W, Qudong Y and Jinhui S: Improvement in pulmonary function of chronic obstructive pulmonary disease (COPD) Patients with osteoporotic vertebral compression fractures (OVCFs) after kyphoplasty under local anesthesia. Int Surg 100: 503-509, 2015.

18. Zhang HT, Chen GD, Yang HL and Luo ZP: Percutaneous kyphoplasty in the treatment of osteoblastic-related spinal metastases. Clin Spine Surg 30: 80-84, 2017.

19. Zhang GQ, Gao YZ, Chen SL, Ding S, Gao K and Wang HQ: Comparison of percutaneous vertebroplasty and percutaneous kyphoplasty for the management of Kümmell's disease: A retrospective study. Indian J Orthop 49: 577-582, 2015.

20. Chen GD, Lu Q, Wang GL, Zou J, Yang HL, Yang Y and Luo ZP: Percutaneous kyphoplasty for kummell disease with severe spinal canal stenosis. Pain Physician 18: E1021-E1028, 2015.

This work is licensed under a Creative Commons Attribution-NonCommercial-NoDerivatives 4.0 International (CC BY-NC-ND 4.0) License. 